\title{
A Proposed Courses Structure for the Preparatory College Year
}

\author{
Mohammed H. S. Al Ashry (Ashry) ${ }^{1}$ \\ ${ }^{1}$ Department of Computer Science, the Community College; Department of Computer Science, the College of \\ Sciences and Literature, Shaqra University, Shaqra, Saudi Arabia \\ Correspondence: Mohammed H. S. Al Ashry (Ashry), Department of Computer Science, the Community College; \\ Department of Computer Science, the College of Sciences and Literature, Shaqra University, Shaqra, Saudi Arabia. \\ Tel: 966-55-990-0033.
}

Received: May 17, 2017

Accepted: May 29, 2017

Online Published: September 14, 2017

doi:10.5430/ijfr.v8n4p53

URL: https://doi.org/10.5430/ijfr.v8n4p53

\begin{abstract}
Colleges in Saudi Arabia receive many college applicants with all sorts of high-school education, knowledge and skills. A large percentage of these applicants have a weak background in the English language, math and science. As a result, most Saudi Universities have a precollege year labeled the preparatory year. During this year accepted applicants are scrutinized to weed out the less qualified, and prepare those with limited deficiencies for college. It is important for a freshman to acknowledge his/her lacking and or lagging in any of the mentioned fields above. Such recognition facilitates the learning process for those who realize their deficiencies. This paper presents samples of a course structure that meets the needs of those with inadequate background in all or two of the three mentioned subjects. The paper offers examples of two curriculum courses in the two main topics, English and math, and suggests a basic curriculum set of courses for the physics discipline. The first semester introduces fundamental material in the two subjects, with more in depth intermediate courses in the second semester. The paper presents a few simple examples for both semesters.
\end{abstract}

Keywords: vocabulary: glossary of words, calculus: math subject, preparatory: introductory period to college, DFC: data flowchart helps in the decision making process

\section{Literature Review}

The concept of a preparatory year as implied and employed in Saudi Arabia is different conceptually and practically from its European counterpart, where it is utilized solely for linguistic purposes. European countries implement the system for different reasons. Preparatory year systems are, mostly, utilized for foreign students who are seeking American equivalent college education degrees, but are lacking or lagging in linguistics in both English and or the host country's native language. The quality of general education in rural Saudi Arabia is lower, on average, than in urban centers in linguistics, math and science making it hard for universities to accept them on the merits of their rural high-schools' grades. Education monitors in Saudi Arabia would be hesitant to say that an A+ student from a rural high-school is equivalent to a $\mathrm{C}$ student in an urban high school. This was the determinant factor behind the establishment of the preparatory year in Saudi Arabia. Not much literature is done on the preparatory year system as it is employed in Saudi Arabia. Some newspapers and weekly magazines articles articulated the problems facing both sides of the educational isle, and presented various solutions to these problems. Technically speaking, however, no journalistic articles examining or considering this specific subject have been published in the related journals.

The knowledge disparity in science and math between rural and urban areas in high school students is as high as that between students in Arabic and English high school systems, respectively. This disparity drove high education governing bodies to introduce the preparatory year system to compensate for such lacking or lagging in science and math. This paper presents a practical example that encapsulates the main subjects of the preparatory year and entails some of the system's requirements in Saudi Arabia.

\section{Introduction}

Foreign students have difficulty grasping the English language because of lacking and or lagging in vocabulary. Clarity of expression, although difficult, can easily be attained with practice and repetition. Vocabulary however, requires understanding, memorization and practice. Subject to technique, however, the two methods complement each other. Students can learn to utilize vocabulary and get a good grasp of clarity in expressing themselves simultaneously. The same methodology applies to math and science. Multiplication is a form of addition; division is 
a form of subtraction. Understanding addition is going half way to multiplication. Learning subtraction simplifies division, which is also the antonym of multiplication.

Learning math simplifies science, especially physics. Physics' theories are mostly logic and some common sense. In physics, the human body can be treated as an object. Comprehending the movement of the human body, its weight, pace and direction facilitates understanding the theory of motion. Considering the movement of the human body while carrying weights, assists in interpreting the relationship between motion, force and energy. The more energy a body has, the more weights it can carry and the more force it poses, kinetically speaking.

\section{Approach and Strategy}

\section{i. English:}

Teaching a language is a process in which the student learns to communicate with others in a completely new tongue. The most important aspect of this process is the order of appropriate material to be learned and how it is put into practice. In cases where learning the language is done for academic and practical purposes it is important to follow a scheme in which the language course is developed bottom up (1). Letters, common vocabularies, phrases followed by grammar maybe an appropriate order in the teaching scheme.

Letters have various shapes, capital, small, recursive and so forth. Vocabularies related to peoples' lives, such as days of the week, months, food products, attire, home products and more are a preference in the early learning stages. Special terminologies and other forms of compounded words add to or change the meaning of a phrase or sentence. The sequence in this learning - teaching scheme leads to sets of illustrative and precise sentences and paragraphs. The above variables are the foundation for a trial test criteria used to gauge the level of incoming or advancing accepted applicants.

The following is a decision flowchart (DFC)(4) Figure 1, for constructing a language course structure. All college majors require a certain level of proficiency in English. The starting point is the criterion by which the student's linguistic level in writing, listening and speech are gauged. An applicant either has the language basics, letters, words and some phrases or is illiterate in the English language. The other two options are either students with intermediate knowledge, a good grasp of the language or just fluent. Illiterate applicants start at level one session, students with basic knowledge start at level-two or three sessions, subject to their level of understanding. Intermediate category students are taken to level-five session; fluent students start at level-eight. The year is made up of two semesters and nine sessions, four sessions in the first and five in the second. Each session focuses on a specific subject in the English language.

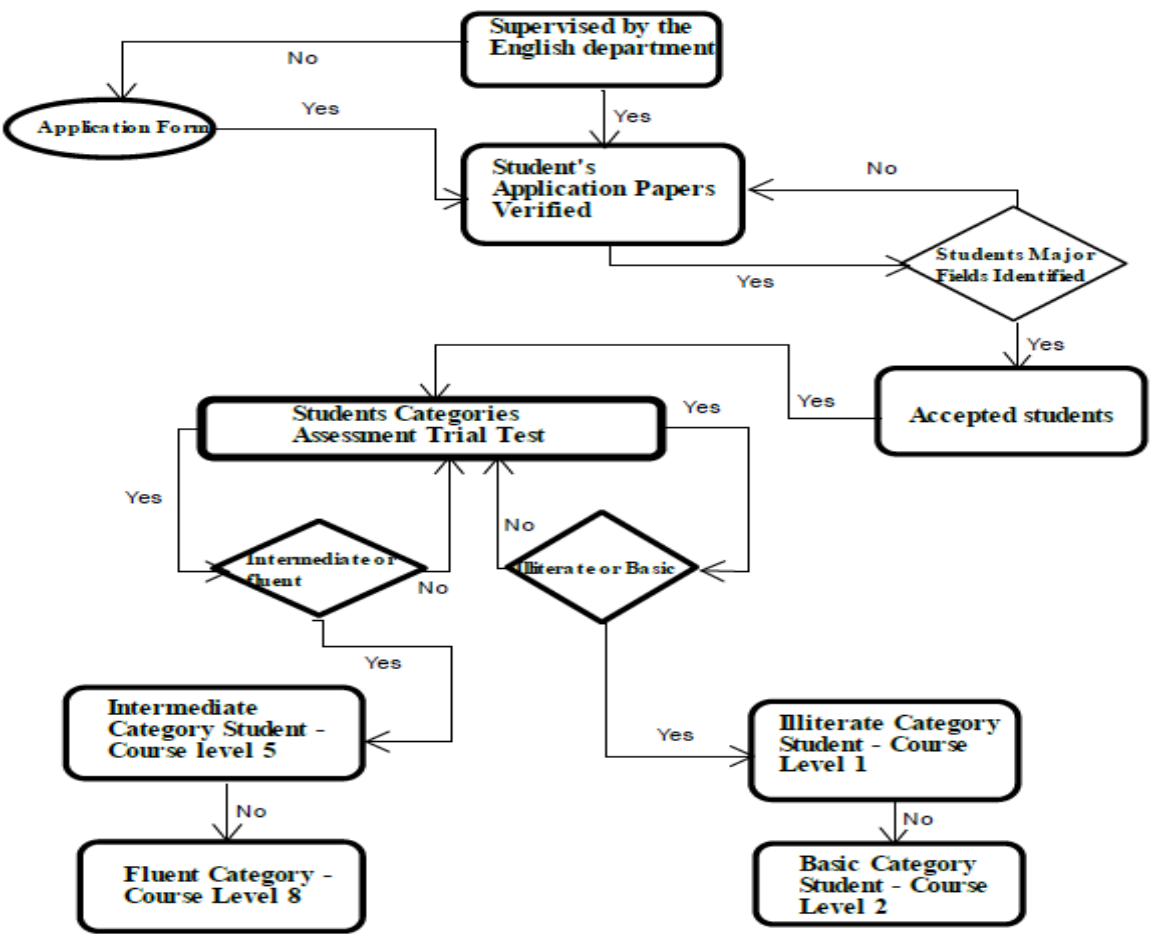

Figure 1. The decision flow chart: Students assessment process 


\section{ii. Math:}

Math is the technical conduit used to explain science. Understanding math facilitates grasping and proving scientific theories. Teaching and learning math intertwines within the science circle. Teaching math concurs with learning science if employed appropriately. For the preparatory year, math can be divided to three main subjects. Incoming students should have practical applications in pre-algebra, and pre-calculus. These topics are sufficient for the requirements of most non-scientific and non-engineering fields. Other math prerequisites for the science and engineering fields are offered during the sophomore or junior years.

The DFC of the math assessment process follows the same logic used in the English assessment. The students are tested on their math skills utilizing the basics of arithmetic, trigonometry, and pre-calculus. Subject to the applicants' major, the first semester may encompass simple inequalities, exponents, arithmetic, quadratics and Boolean algebra. A short, simple session on pre-pre-calculus and trigonometry should be included towards the end of the semester. The $2^{\text {nd }}$ semester should delve more in depth into pre-calculus, algebra functions, especially geometry and trigonometry. The following DFC, Figure 2 provides us with a view into the procedure of assessing and processing preparatory year's applicants.

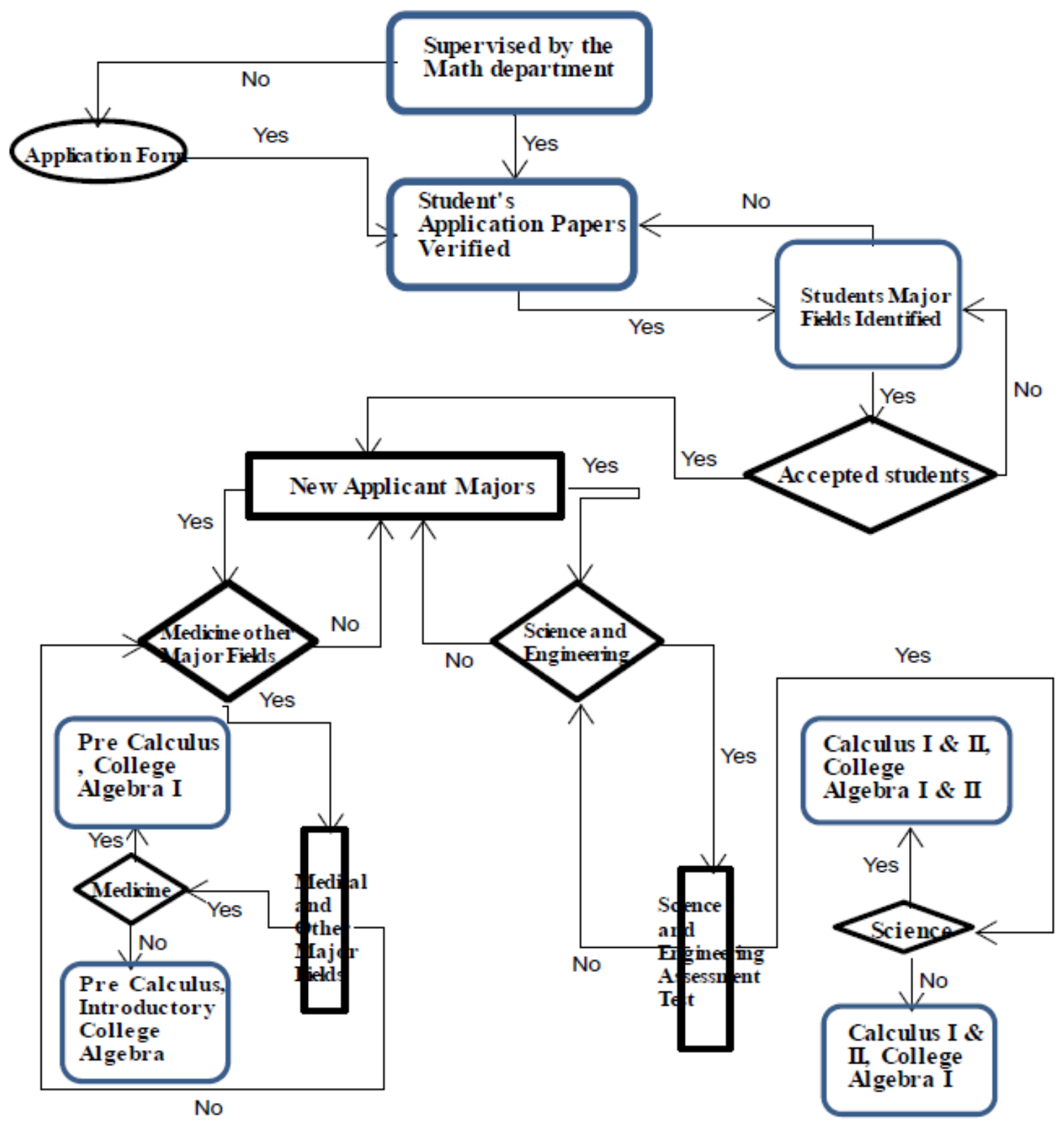

Figure 2. The decision flow chart: Students math assessment process 


\section{iii. Science:}

Science emphasizes and employs math extensively, especially physics. The same approach used in implementing math in the prep year is applicable with physics. The DFC for science follows the same logic utilized in the math department. Science and engineering colleges require much more physics as prerequisites for the various theoretical and applied fields, respectively, in comparison to humanity and linguistic disciplines. Certain nonscientific disciplines may have more science prerequisites for the higher level studies; for such disciplines, the prerequisites can be introduced within the courses calendar. The following DFC, Figure 3, sets the boundaries for the physics material taught during the prep year.

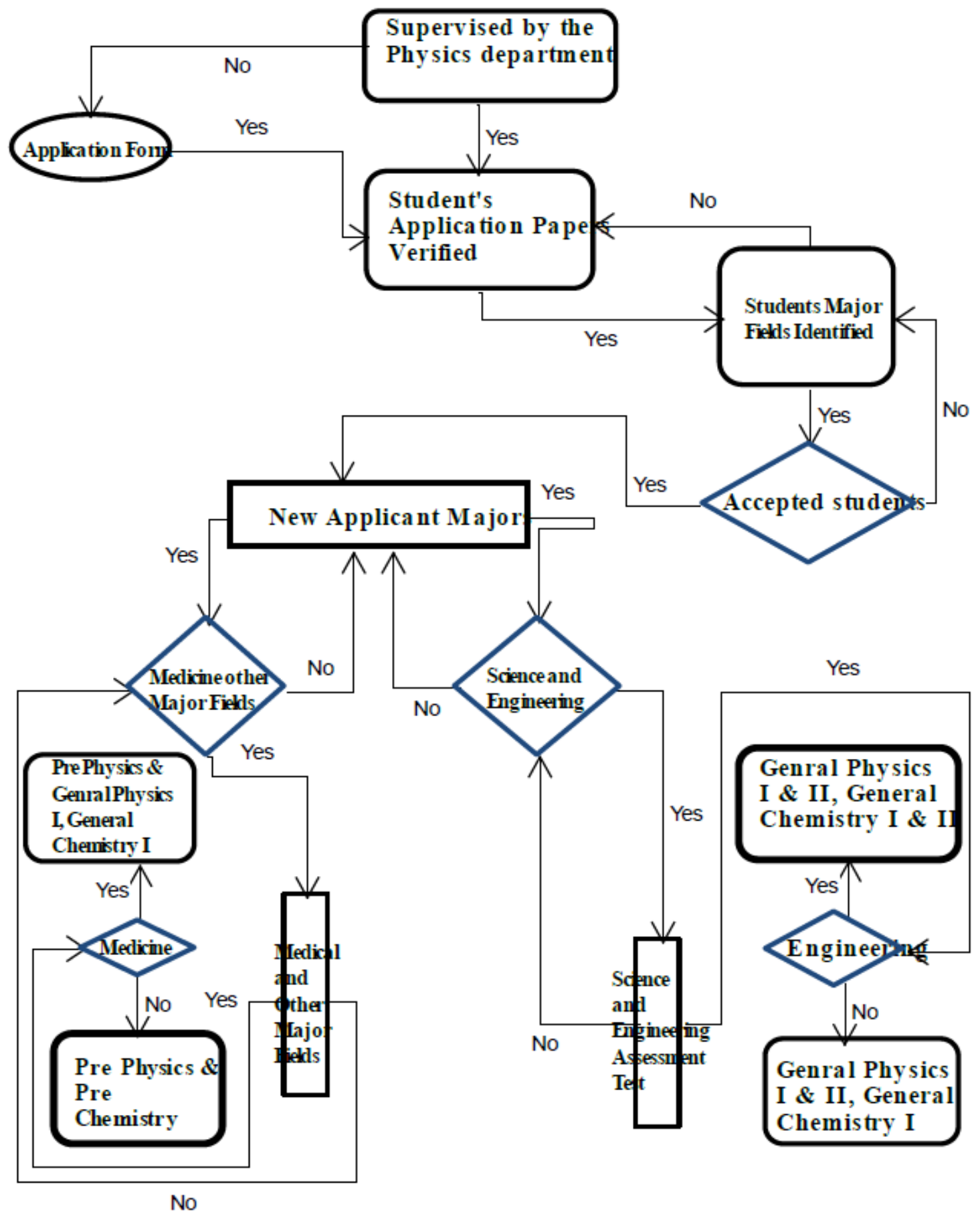

Figure 3. The decision flow chart: Students physics assessment process 


\section{Methods and Techniques}

\subsection{English Structure}

Non-English speaking students require a great in-depth understanding of their learning language as a prerequisite to understanding the material at hand. Medicine and many other scientific disciplines still require English as a learning vehicle. The following are sets of examples for learning English at various levels:

i. Low level communication: This part concentrates on getting more understanding of our surrounding.

\section{a) A visual lesson:}

This is a simple example of a first level set of words with visual illustration Figure 4. This tells the students the meaning of the word without explanation, the picture speaks for itself (1). The words are represented with an image of the object.
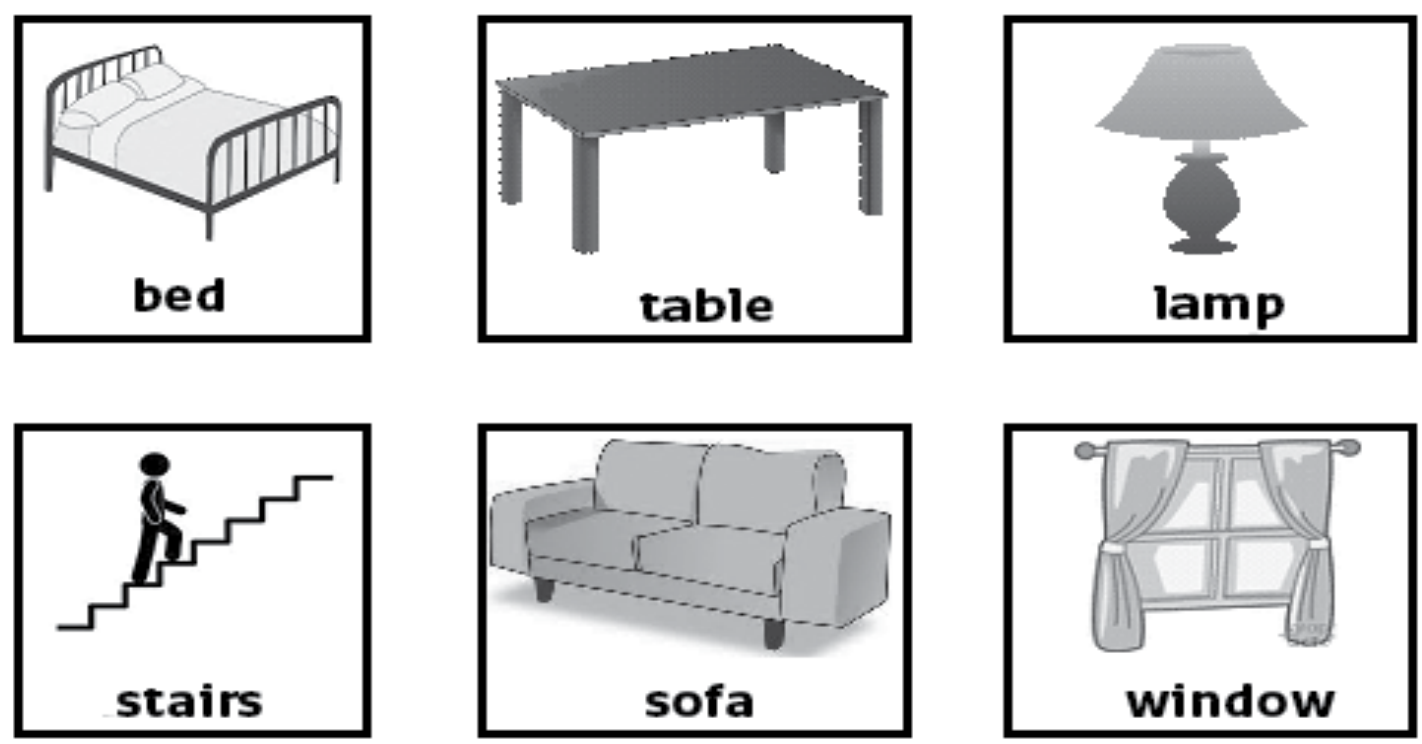

Figure 4. Simple one word visual examples

The following is a level 2-3 example, the student is faced with a phrase exhibited with visual illustration, and an example with no visual illustration as in Figure 5, (1).

\begin{tabular}{|l|l|}
\hline Close the door. & Raise your hand. \\
\hline
\end{tabular}




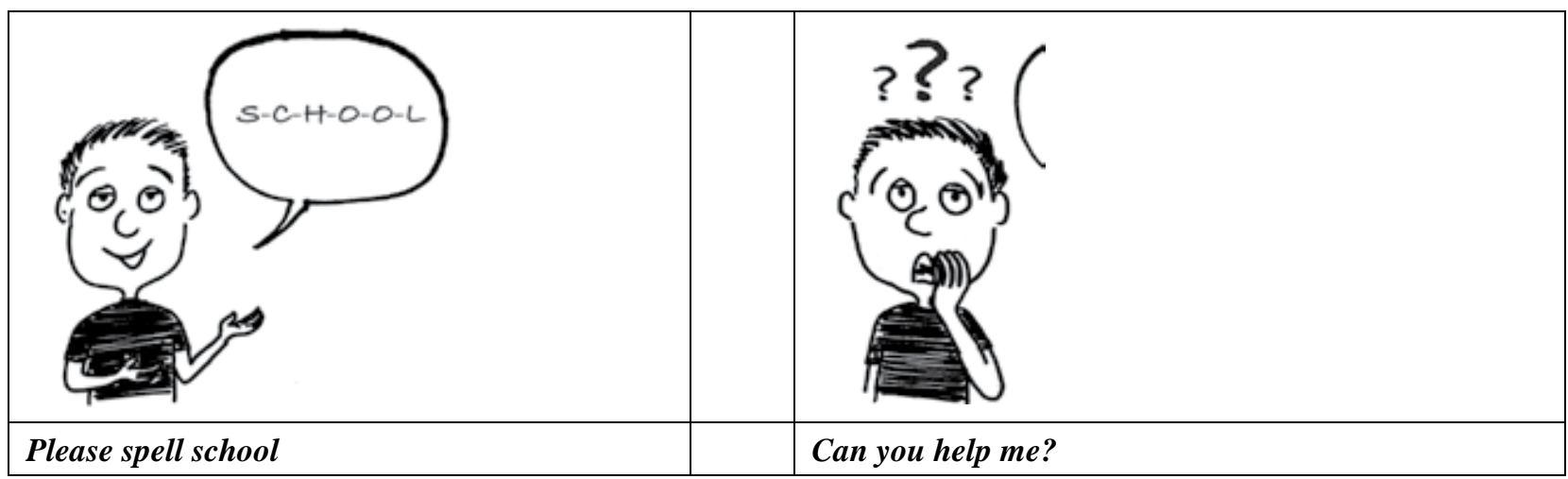

Figure 5. English examples with phrases and visual illustration

Figure 6, illustrates easy visual and nonvisual questions with multiple choice answers. Students can read the answers with and without illustrative visuals.

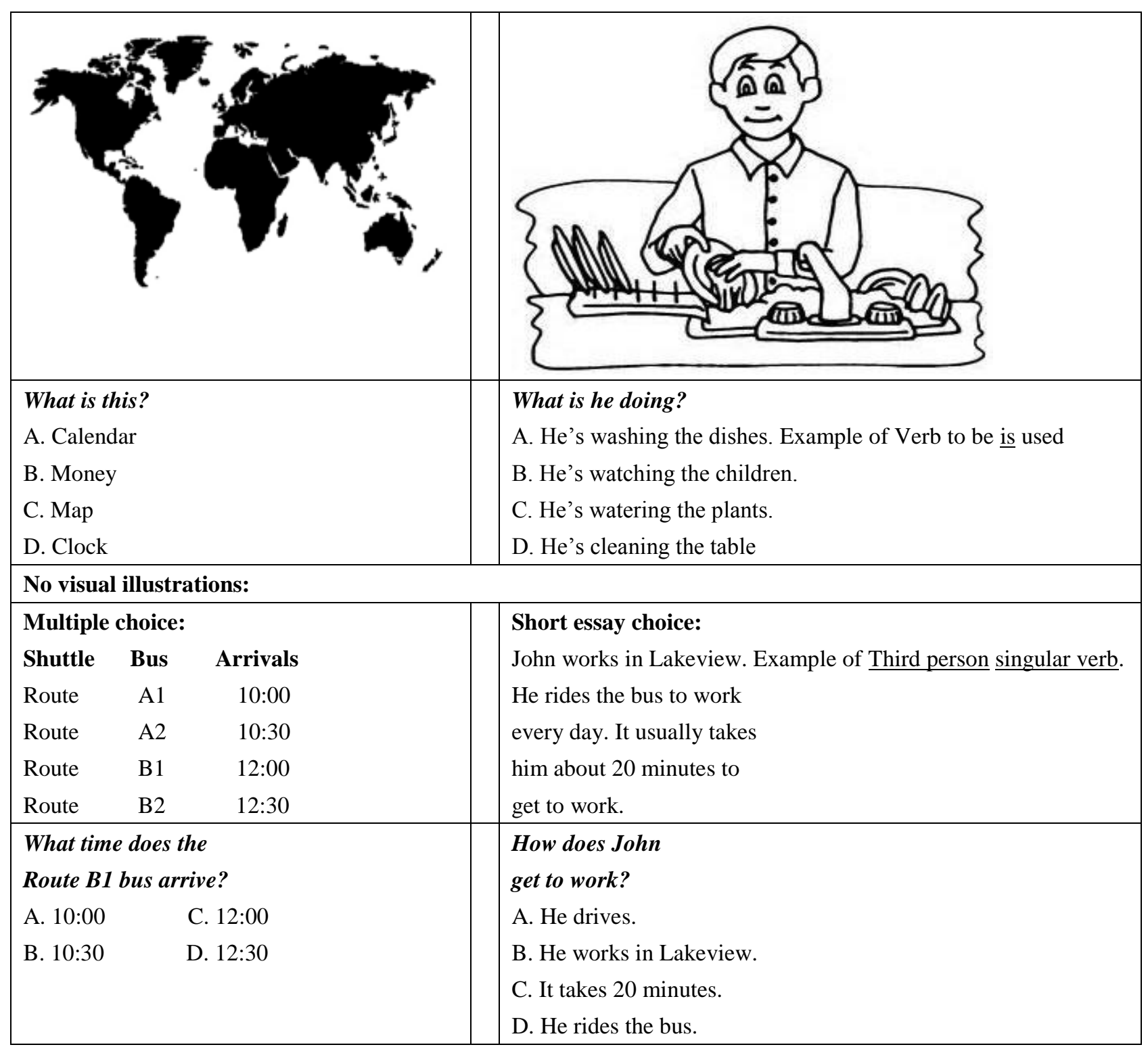

Figure 6. English examples with and without visual illustration 
The following is an example that can be employed in levels 4-5. On the right is a set of sentences employing the words on the left. The student is expected to do both write the meaning of the word on the left in the student's mother tongue, and then use it in a different sentence, in English, on the line below. The sentences emphasize meaning and are grammatically appropriate to broaden the students' knowledge of relating nouns and adjectives to verbs. It may be noted that only the verb to be is and are have been used to simplify the sentences (2):

all All sugar is sweet.

from $\quad$ Her clothes are from France. Example of Possessive adjective

to $\quad$ Potatoes are from $\$ .30$ to $\$ .50$.

but All chickens are from eggs, but not all eggs are from chickens.

the The top of the map is north.

of This is a map of Mexico.

Example of Verb to be $\underline{\text { is }}$

between Texas is between Florida and California.

also

Mary is in London and John is also.

The following is an example of levels 8-9 lessons. This is a descriptive paragraph about the body of a young lady named Mary and a young man named John. The objective of this paragraph is to illustrate figuratively the names of the human body parts. In the process, the student is asked questions on the paragraph within a set period of time. This paragraph tests the students' reading speed, observation and comprehension. Again, it is worth noting that the entire paragraph uses only verbs to be is and are, along with possessive adjectives (2):

\section{Body:}

Mary's body is beautiful. Her legs are the right size, not too long and not too short. Her face, a part of her head, is beautiful. Her lips are sweet. Her brown eyes are fresh. Mary's hair is black. Her ears are little and her nose is short. It is in the middle of her beautiful face. It is between her beautiful eyes and her sweet mouth. Her tongue is in her mouth and her teeth are in it also. They are very beautiful and white. Her chin is the right size for her face. Her long neck is between her head and her shoulders. Her throat is a part of her neck. Her arms are long. Her hands are the right size, not too big and not too little. Her fingers are very long. There is a ring on the third finger of her left hand. John's body is not too beautiful, but it is, without question, big! His chest is big. His two lungs are in it. His heart is between them. His stomach is close to his heart. His brain is in his head. There are many nerves in his body. His Adam's apple is a part of his neck. There are many different muscles in all the parts of his body. His back bone is between his head and his seat or bottom. John's blood is red. It is in all the parts of his body. There are many little bones in his big feet. His toes and heels are parts of his feet. There are five toes on his right foot, but only four on his left one. John's leg muscles are very good. His legs are long. His knees are parts of his leg. They are in the middle of his legs. His hands are big and his fingers are long, but his thumbs are a little short. At this time, there is no ring on his left hand.

\section{ii. High level communication:}

This relates to communicating with college associates, faculty members and or writing a science paper. This requires a higher level of communication vocabulary. It involves more sophisticated words and phrases used in scientific research. The following is part of an abstract of a science paper on heat: 


\section{Heat Dissipation (3):}

Heat sinks were invented to absorb heat from within an electronic circuit conduct then dissipate and or radiate this heat to the surrounding supposedly, ventilated space, at a rate equal to or faster than that of its buildup. Ventilation was not initially recognized as an essential factor to thermal dispersion however as electronic circuit-boards continued to heat up, circuit failure became a problem, forcing the inclusion of miniaturized high speed fans.

A student may not be expected to write the previous short paragraph, however, are predisposed to do so sometime in the future if are involved in a related science research. Short paragraphs such as the one above can be utilized to expose students to higher level writing. This can be employed to test their vocabulary and comprehension.

\subsection{Math Structure}

Math is one of those subjects either hated or loved by students, subject to their proclivity. The following is a set of examples of math subjects in pre-calculus, algebra, and calculus. Algebra includes many topics some inclined to computer software use, and some tailored to physics and or engineering. Geometry and trigonometry are utilized by scientists and engineers, quadratics mostly used by scientists and statisticians, while Boolean is a subject mostly visited by computer engineers and computer design scientists. An example of each will be presented in the following paragraphs.

Calculus, on the other hand is a subject for all of the above. Its complexity stems from unsolved algebraic equations mathematicians are trying to solve using advanced theories in math such as tensors. Calculus utilizes the so called very discrete fractions of a number to relate the bigger parts. An example will be offered in the following sections (5).

\section{a. Algebra:}

i. Geometry: Geometry deals with points, lines, areas and volumes. An example of geometric numbers and sequences provides us with data on the related arithmetic numbers as follows in Figure 7:

\begin{tabular}{|l|l|l|l|l|l|}
\hline $\mathrm{n}$ & 1 & 2 & 3 & 4 & 5 \\
\hline $\mathrm{S}_{\mathrm{n}}=\mathrm{n}^{2}$ & 1 & 4 & 9 & 16 & 25 \\
\hline $\mathrm{S}_{\mathrm{n}}=\left(\sum \mathrm{n}\right)^{2}$ & 1 & $3^{2}$ & $6^{2}$ & $10^{2}$ & $15^{2}$ \\
\hline $\mathrm{S}_{\mathrm{n}}$ & 1 & 9 & 36 & 100 & 225 \\
\hline
\end{tabular}

Figure 7. Geometric numbers and sequences

The following Figure 8 is a very simple example of a geometric problem (6).

\begin{tabular}{|l|l|}
\hline Given: a triangle with angle $3=90^{\circ}$ & \\
Prove: angle1 and angle 2 are complementary & \\
& \\
& \\
\hline Statements & Reasons \\
\hline 1. angle $3=90^{\circ}$ & 1. Given \\
\hline 2. angle $1+$ angle $2+$ angle $3=180^{\circ}$ & 2. Sum of angles in triangle $=180$ \\
\hline 3. angle $1+$ angle $2+90^{\circ}=180^{\circ}$ & 3. Using substitution \\
\hline 4. angle $1+$ angle $2=90^{\circ}$ & 4. Subttotal Prop. of equality $(180-$ angle $3=90)$ \\
\hline 5. angle 1 and angle 2 are complementary & 5. Definition of complement to angle 3 \\
\hline
\end{tabular}

Figure 8. An example of a geometric problem 
For those who seek an accurate average of a set of variables geometry provides one:

Geometric average $=\left(\Pi \mathrm{A}_{\mathrm{i}}\right)^{1 / \mathrm{n}}=\left(\mathrm{X}_{1} * \mathrm{X}_{2} * \mathrm{X}_{3} * \ldots \mathrm{X}_{\mathrm{i}}\right)^{1 / \mathrm{n}} \quad$ for $\mathrm{i}=1 \ldots \mathrm{n}$

\section{ii. Trigonometry:}

Figure 9 provides an example of a simple trigonometric problem for solving triangular problems.

Given $\operatorname{Sin} \theta_{1}=\mathrm{c} / \mathrm{a}$
Given $\operatorname{Cos} \theta_{1}=\mathrm{a} / \mathrm{b}$
Calculate $\operatorname{Tan} \theta_{1}$
We know that
Tan $\theta_{1}=\left(\operatorname{Sin} \theta_{1} / \operatorname{Cos} \theta_{1}\right)$
$\begin{aligned} & \text { So: } \\ & \left(\operatorname{Sin} \theta_{1} / \operatorname{Cos} \theta_{1}\right)=(\mathrm{c} / \mathrm{a}) /(\mathrm{a} / \mathrm{b}) \\ & (\mathrm{c} / \mathrm{a}) /(\mathrm{a} / \mathrm{b})=\operatorname{ca} / \mathrm{ab} \\ & \text { ca/ab }=\mathrm{c} / \mathrm{b} \\ & \text { this gives us: } \operatorname{Tan} \theta_{1}=\mathrm{c} / \mathrm{b}\end{aligned}$

Figure 9. An example of a trigonometric problem

\section{iii. Inequality:}

Inequalities have many properties, subject to type of math operation and or whether the inequality is compounded and whether it is one, two or even three dimensional. I will provide a simple multiplication one dimensional compounded inequality for this example:

Take the scalar number variables $a, b$, and $c$

$$
\mathrm{C}<=0, \quad 10>=\mathrm{a}>=5, \quad 0<\mathrm{b}<=3
$$

And using multiplication with the logical word AND, and the logical word OR we have:

$$
\begin{gathered}
0<\mathrm{a} * \mathrm{~b} \text { AND } \mathrm{a} * \mathrm{~b}<=30 \quad \text { are limited to the values between }>0 \text { and }<=30 \\
0<\mathrm{a} * \mathrm{~b} \text { OR } \mathrm{a} * \mathrm{~b}<=30 \quad \text { are not limited, infinite on both sides of the } \mathrm{a} * \mathrm{~b} \text { values. } \\
\text { iv. Exponents: }
\end{gathered}
$$

Exponentials simplify mathematical calculations by simplifying infinitely large or small numbers. The following list of numbers can be simplified using exponential derivatives (6):

The electron charge to mass ratio $=-175880000.0$ and using exponentials $=1.7588 \times 10^{8}$.

The electron mass $\mathrm{m} \sim=91096000000000000000000000000.0 \mathrm{~g}$, and using exponentials $=9.1096 \times 10^{28}$.

So we can see the importance of exponentials for such numbers and how it is almost impossible to write a lot of functions related to chemistry and physics without the help of exponentials.

\section{v. Arithmetic:}

Arithmetic is simply the operations of addition, subtraction, multiplication and division. A simple example of an arithmetic function is the arithmetic mean. The total value of a multiple of variables divided by the number of these variables is the arithmetic mean. For example, the number of students in a class $=\mathrm{n}$, with grades $\mathrm{X}_{\mathrm{i}}$ can provide us with an arithmetic average $\bar{A}=\sum_{1}\left(X_{i} / n\right)$, this is the total students' grades divided by the number of students.

\section{vi. Quadratic:}

Quadratic equations have always been utilized for calculating the values of a function on the basis of one or more variables, such as $y=x^{3}+c$, where $c$ is a constant. There are many forms of quadratic equations that can be factored to provide a simplified form that can be implemented on a graph. $(\mathrm{x}-1)^{*}(\mathrm{x}+1)=\mathrm{x}^{2}-1$ is another factorable form of quadratics. Graphing the second part is easier than the first.

\section{vii. Boolean:}


Boolean algebra is a form of math that is very important to designing electronic digital circuits. It was essential in designing the early super computers by Seymour Cray. The following table in Figure 10, is a simple truth table of the Boolean functions and operations.

\begin{tabular}{|l|l|l|l|l|l|l|l|l|}
\hline $\mathrm{x}$ & $\mathrm{y}$ & $\sim \mathrm{x}$ & $\sim \mathrm{y}$ & $\mathrm{x} \wedge \mathrm{y}$ & $\mathrm{x} \vee \mathrm{y}$ & $\mathrm{x} \quad \mathrm{e}^{*} \wedge \mathrm{y}$ & $\mathrm{x} \vee \mathrm{e} \vee \mathrm{y}$ \\
\hline $\mathrm{T}$ & $\mathrm{T}$ & $\mathrm{F}$ & $\mathrm{F}$ & $\mathrm{T}$ & $\mathrm{T}$ & $\mathrm{F}$ & $\mathrm{F}$ \\
\hline $\mathrm{T}$ & $\mathrm{F}$ & $\mathrm{F}$ & $\mathrm{T}$ & $\mathrm{F}$ & $\mathrm{T}$ & $\mathrm{T}$ & $\mathrm{F}$ \\
\hline $\mathrm{F}$ & $\mathrm{T}$ & $\mathrm{T}$ & $\mathrm{F}$ & $\mathrm{F}$ & $\mathrm{T}$ & $\mathrm{T}$ & $\mathrm{F}$ \\
\hline $\mathrm{F}$ & $\mathrm{F}$ & $\mathrm{T}$ & $\mathrm{F}$ & $\mathrm{F}$ & $\mathrm{T}$ & $\mathrm{T}$ \\
\hline *: e stands for exclusive & \multicolumn{7}{l}{} \\
\hline
\end{tabular}

Figue 10. An example of Boolean algebra truth table

This table represents the basic AND - OR True - False relationships. Most modern CPU designs are based on functions utilizing these relationships.

\section{viii. Probability:}

Probability of an event is based on the relationship between the various variables. Probability of getting a head in a coin flip is $1 / 2$, there are two possibilities, head and tail, so head is one head / (one head + one tail). Probability of the number 1 in a dice flip is $1 / 6$, number $1 /$ numbers on a dice is 6 . Three dices with six numbers on each and getting the number 1 on all the dices is $(1+1+1) /(6 * 6 * 6)=3 / 216=1 / 72$. The probability of an event taking place is $=$

Total number of events selected divided by the total number of possibilities. So for a car plate with the number $123 \mathrm{abc}$

The possibility of finding the car is ( $6 / 28 ! * 10$ !,) which is practically an infinitesimal number or possibility.

\section{b. Pre-Calculus:}

\section{i. The limits:}

$\dot{y}^{\prime}=\mathrm{f}^{\prime}(\mathrm{x})=\operatorname{limit}(\Delta \mathrm{x} \rightarrow 0)(\mathrm{f}(\mathrm{x}+\Delta \mathrm{x})-\mathrm{f}(\mathrm{x})) / \Delta \mathrm{x}=\mathrm{f}(\Delta \mathrm{x}) / \Delta \mathrm{x}=$ undefined as the function of $\mathrm{f}(\Delta \mathrm{x})$ is not known and $\Delta \mathrm{x}$ $\rightarrow 0$

but for $\mathrm{f}(\mathrm{x})=\mathrm{x}$ we have $\mathrm{f}^{\prime}(\mathrm{x})=\operatorname{limit}(\Delta \mathrm{x} \rightarrow 1)((\mathrm{x}+\Delta \mathrm{x})-\mathrm{x}) / \Delta \mathrm{x}=1$

\subsection{Physics Structure}

Physics is much broader than the case with math. It is appropriate to be general in defining the material to be categorized for a specific field of study. So to be able to define certain topics in physics for certain fields of study, all we have to do is identify and define the appropriate topic in physics to the field of study at hand. The following table Figure 11, identifies and defines appropriate topics that suit the selected field of study:

\begin{tabular}{|c|c|c|c|c|c|}
\hline Physics topics & $\begin{array}{l}\text { Field of } \\
\text { study }\end{array}$ & Medicine & $\begin{array}{l}\text { Science } \\
\text { physics) }\end{array}$ & Engineering & Other \\
\hline $\begin{array}{l}\text { Short topics } \\
\text { energy and elec }\end{array}$ & $\begin{array}{l}\text { on motion, } \\
\text { tricity, }\end{array}$ & All & All & All & Minimal \\
\hline Pre college phy & sics & All & All & All & Minimal \\
\hline General physic & & First course & $\begin{array}{l}\text { The two full } \\
\text { semesters }\end{array}$ & All & Non \\
\hline $\begin{array}{l}\text { Topics of } \\
\text { mechanics, e } \\
\text { atomic physics }\end{array}$ & $\begin{array}{l}\text { advanced } \\
\text { lectricity or } \\
\end{array}$ & None & Subject to inclination & $\begin{array}{l}\text { One or two courses on } \\
\text { mechanic, electricity and } \\
\text { atomic physics, subject to } \\
\text { major }\end{array}$ & None \\
\hline
\end{tabular}

It is important to realize that all of the above topics intertwine with one another in more than one way. Energy is based on some form of motion or mechanics. Electromagnetism is a producer of energy and interacts with mechanics and atomic energy. Radiation can be partially a product of electrical and mechanical heat or energy, and so on. 
The following is a description of the material in the previous table in Figure 12:

\begin{tabular}{|c|c|}
\hline Material & Description \\
\hline $\begin{array}{l}\text { Short topics on } \\
\text { motion, energy and } \\
\text { electricity, }\end{array}$ & $\begin{array}{l}\text { The topics cover low level problems on velocity, acceleration, momentum, force, work and } \\
\text { energy. The kinetic aspects of motion and dynamics of energy should be explained with } \\
\text { simple examples. Electro-dynamic conceptual problems relating energy to electricity are } \\
\text { explained in simple small details. }\end{array}$ \\
\hline Pre college physics & Two semesters of general high-school level physics with emphasis on motion and energy \\
\hline General physics & $\begin{array}{l}\text { Two semesters of college physics focusing on motion and energy during the first semester. } \\
\text { The second semester focuses on electricity, electromagnetism, relativity and atomic physics. }\end{array}$ \\
\hline $\begin{array}{l}\text { Topics of advanced } \\
\text { mechanics, } \\
\text { electricity and } \\
\text { atomic physics }\end{array}$ & $\begin{array}{l}\text { This is an in depth study on analysis of vibration and celestial mechanics and dynamics, } \\
\text { particle motion in three dimensions and fluid mechanics. Concepts and theories of } \\
\text { electromagnetic fields and waves, electrostatics fields, special and general relativity, quantum } \\
\text { mechanics of particles in three dimensions. All of the above are subject to major fields of } \\
\text { study. }\end{array}$ \\
\hline
\end{tabular}

Figure 12. Material description of the courses

\section{Results}

The previous segments presented examples of simple English and math lessons. The decision flow charts present the best technique for the selection process. A set of courses that meet the discussed major fields of study are emphasized through the simple examples displayed in the previous sections. It is important to realize that the objective is to raise the level and quality of both the students and faculty in order to have only the qualified students advance to the next level. The samples highlight the importance of starting at the level the students understand. In English, simple words were used, and in math, the simplest samples were presented in each of the sub-subjects.

\section{Conclusion}

After writing the above and having gone through quite a bit of math and physics, not to mention that I had to study English as a second language a few decades ago. I have to say that the preparatory year, as a requirement, is a short term option. Many years from now, the quality of general education in Saudi Arabia will hopefully improve, and the need for the prep year will cease to exist. At such time, regular calendars and schedules will be employed. The students entering college in Saudi Arabia, however, have a very weak background in all of the above topics. Most do not know the English alphabet. Very few know anything on algebra, all together, not to mention calculus or physics. A wide ranging material covering all of the above must be included in the prep year. English is a necessity for those majoring in medicine, science and engineering, as most of the advanced publications in those fields are written in English. For those planning on going to the science and engineering fields, it is strongly recommended to take as much of the above in physics, math and English. Those majoring in other fields, and subject to their field of study, some topics in math and physics are recommended; especially psychology and sociology majors.

\section{References}

Charles E. Mortimer. (1979). Chemistry: A Conceptual Approach. MUHLENBERG COLLEGE; Litton Educational Publishing Company, Inc.

Earl L. Whitney. (2016). Math Handbook: Formulas, Processes and Tricks - Algebra and Calculus (Version 2.8). Retrieved April 19, 2016, from www.mathguy.us

ESL Learner Persistence Committee. ESL Student Guide. ESL English as a Second Language: Beginning Student Guide. Retrieved from www.sdce.edu/programs/esl

James Martin, \& Carma McClure. (1988). Structured Techniques: The Basis for CASE. Prentice HALL, Englewood Cliffs, New Jersey.

Mohammed H. Ashry. (2015, February). Augmenting the Heat Sink for Better Heat Dissipation. Circuits and Systems, 6(2).

Richard R. Lane. (2009). Lanes English as a second Language. Lane Press. 